\title{
Robson classification of Caesarean Section cases in Armadale health service in one-year period
}

\author{
Negar Hosseinzadeh, Ljiljana Ilic-Jeftic \\ Armadale Health Service, Perth, Australia
}

Aim: The aim of this audit is to conduct analysis of Caesarean Section (CS) cases using Robson Classification. By identifying the groups of women with highest CS rate, effective measures can be proposed and implemented to reduce it.

\section{Materials and method:}

All deliveries in obstetrician department of Armadale health service, Western Australia, from July 2015 to June 2016 have been included. Robson classification had been applied to all caesarean section deliveries using departmental records. Robson TenGroup Classification is a system that classifies women into 10 groups based on their obstetrics characteristics (parity, previous CS, gestational age, onset of labour, foetal presentation and the number of foetuses).

Results: From total 2493 deliveries, 523 was done with Caesarean section method (the annual caesarean section rate was $20.97 \%$ ).About forty percent
(213 cases) were patients with single cephalic pregnancy and history of caesarean section (group 5). Induced nulliparae single cephalic was the second largest group with 77 cases ( $14.72 \%$ ) and nulliparae patients with single cephalic who went through spontaneous labour but ended up with CS were in the third place ( $13.57 \%$ ) .

Conclusion: By using Robson classification, we divided caesarean section cases into ten groups. Overall CS rate in Armadale health service is approximately ten percent below national rate $(32 \%)$. Our results showed that patients with previous caesarean section was the largest group therefore it is important to closely monitor and avoid unnecessary CS in low risk patients specially in nulliparous mothers as it can increase their chance to have CS in further pregnancies. In addition, vaginal birth after caesarean (VBAC) should be encouraged in all multipara patients. 